\title{
A LATINIDADE DO CONCEITO DE AMÉRICA LATINA
}

\author{
PEDRO DE ARAUJO QUENTAL \\ Universidade Federal Fluminense
}

\section{Introdução}

Os conceitos possuem uma história, surgem em circunstâncias sociais e políticas específicas e, ao longo de sua recepção pelas seguidas gerações, acumulam uma variedade de significados e usos, fazendo coexistir, no tempo presente, formas linguísticas de momentos históricos distintos (Jasmim e Feres Júnior, 2006). Os conceitos não são destituídos de valoração, ao contrário, carregam sentidos e significados que refletem expectativas, interesses e percepções de mundo também específicas aos contextos em que surgiram e aos atores sociais que os criaram, ou deles fizeram uso (Jasmim, 2005). E, mais do que isso, os conceitos também possuem uma dimensão prática e de ação no mundo, uma vez que criam e delimitam nossas formas de interpretar a realidade e, portanto, também de nela intervir (Richter, 2006; Jasmim e Feres Júnior, 2006).

Neste sentido, recuperar a história dos significados e usos políticos de um conceito constitui uma maneira de reconhecer não simplesmente as coisas e fatos que estes buscam representar, mas a própria forma como moldam nosso pensar e agir na realidade. Por isso, a importância de traçar sua história, seus usos e sentidos passados. Uma vez conscientes dos enquadramentos que um conceito imprime em nossos modos de interpretar e intervir na realidade, somos capazes de formular alternativas aos ângulos consolidados de mirada para o mundo (Richter, 2006).

Qual a história do conceito de América Latina? Que significados carrega consigo? Que maneiras de conceber o que é a realidade este conceito nos impõe? Qual a singularidade de fatos e estado de coisas que ele procura representar, delimitar e descrever? Em que contexto político e social surgiu? Por quais atores sociais foi formulado e empregado, e com que usos e sentidos? 
Neste trabalho, buscamos traçar alguns aspectos da história do conceito de América Latina, evidenciando os contextos e a dimensão política referentes à sua invenção, formulação e uso. Com isso esperamos trazer uma contribuição para desnaturalização deste conceito, reconhecendo as consequências políticas e epistêmicas produzidas pelo mesmo.

O pano de fundo de nossa discussão encontra-se vinculado ao campo de conhecimento da História dos Conceitos, que possui como referência, no Brasil, os trabalhos de João Feres Júnior e Marcelo Jasmim e, no âmbito internacional, as pesquisas de Quentin Skinner, em perspectiva inglesa, e Reinhart Koselleck, em perspectiva alemã. Entre outros aspectos, a História dos Conceitos busca evidenciar o caráter contextualizado e sua dimensão de prática e ação no mundo, que todo conceito possui.

A opção pelo diálogo com esta corrente de pensamento adveio, justamente, da abertura que este nos proporciona para a problematização da aparente estabilidade e imutabilidade do conceito de América Latina, comumente associado à simples região ou recorte geográfico, categoria de análise destituída de implicações políticas.

Contudo, foi acompanhando as reflexões do semiólogo Walter Mignolo (2007), em seu livro La idea de América Latina, $e$ as contribuições de autores como Enrique Dussel (2005), Aníbal Quijano (2005), Arturo Escobar (2003), Santiago Castro-Gómez (2007), Ramón Grosfoguel (2006; 2007), Porto-Gonçalves (2002; 2003; 2005; 2006), entre outros, que aprofundamos as questões oferecidas neste artigo.

Os autores acima citados são protagonistas de uma corrente teórica denominada pensamiento decolonial ou, nas palavras de Escobar (2003), grupo de investigação da modernidade-colonialidade latino-americano. Seus trabalhos pontuam uma perspectiva crítica em relação ao padrão predominantemente eurocêntrico do fazer científico, bem como localizam, no período histórico de formação do sistema-mundo moderno-colonial e constituição da América, as matrizes das relações sociais e de poder que fundamentam e organizam a vida das sociedades na contemporaneidade.

A corrente teórica do pensamiento decolonial aproxima-se da perspectiva do pós-colonialismo, mas diferencia-se deste campo, entre outros aspectos, justamente por se configurar como teoria elaborada a partir de outro lócus de enunciação: a América Latina, um espaço-tempo constituído a partir de experiências históricas forjadas no colonialismo dos séculos XVI ao XIX e capitaneados por Espanha e Portugal. No póscolonialismo, as referências são tributárias da experiência colonial na Ásia 
e África, entre os séculos XVIII e XX, e comandados por Inglaterra, França e Alemanha.

A opção por trabalhar com este grupo de autores adveio do caráter central que a dimensão territorial possui em suas argumentações, bem como da posição igualmente central que a própria constituição de uma região denominada América/América Latina ocupa no conjunto de suas reflexões.

Em certa medida, as considerações levantadas pela corrente teórica do pensamiento colonial são tributárias de outras linhas de pensamento latino-americanas, como, por exemplo, a teoria da dependência, surgida nas décadas de 1950 e 1960, no âmbito dos debates da Comissão Econômica para a América Latina e o Caribe (CEPAL), em que, influenciados pelos trabalhos pioneiros de Raúl Presbisch e Celso Furtado, autores como Fernando Henrique Cardoso e Enzo Falleto, André Gunder Frank, Rui Mauro Marini, Theotônio dos Santos, entre outros, buscaram refletir sobre a questão do desenvolvimento econômico na América Latina no contexto da redefinição do cenário político e econômico mundial do Pós-Segunda Guerra.

Como bem demonstra Oliveira (1998), na perspectiva cepalina, o processo de industrialização era compreendido como a principal solução para a superação da condição de subdesenvolvimento dos países latinoamericanos. Com a industrialização, o problema das trocas internacionais desiguais seria superado, uma vez que permitiria saírem da posição de meros produtores de bens primários. os países latino-americanos.

Contudo, mesmo após o intenso processo de industrialização, vivenciado por países como México, Argentina e Brasil, a dependência econômica e a não resolução de problemas sociais básicos permaneceram marcando a realidade desses países. A teoria da dependência surge, então, como uma forma de explicar essa nova condição de muitos dos países latino-americanos: industrializados, mas ainda marcados pela situação de dependência. De acordo com os autores da teoria, a condição de dependência se explica não simplesmente pela deterioração dos termos de troca entre países produtores de bens primários e países industrializados, como advogava a tese cepalina, mas, sobretudo, pela forma como internamente a cada país, se estrutura a relação entre classes e a exploração através do processo de produção e controle do trabalho pelas classes dominantes (Oliveira, 1998).

Apesar das diferenças de perspectivas existentes entre seus autores, sobretudo, no que diz respeito às propostas para superação da condição de 
dependência, em linhas gerais, a teoria da dependência aponta que a situação de subdesenvolvimento das economias latino-americanas foi produzida historicamente a partir do momento em que a expansão do capitalismo comercial e, posteriormente, industrial, vinculou e inseriu, em um mesmo mercado de caráter mundial, economias com sistemas produtivos muito diversos que passaram a ocupar posições e funções distintas e desiguais na estrutura global de produção do sistema capitalista, constituindo relações entre centro e periferia (Cardoso e Falleto, 1969).

Neste sentido, a teoria da dependência refuta as pressuposições de isolamento espacial e histórico que apontam o subdesenvolvimento como sendo uma etapa ou estágio para o desenvolvimento. Ao contrário, argumentam que o subdesenvolvimento não é falta ou carência de desenvolvimento, mas uma forma de desenvolvimento, produto de uma relação histórica de dominação política e econômica (Feres Júnior, 2005). Subdesenvolvimento e desenvolvimento são, portanto, faces opostas de uma mesma moeda, sendo um tão desenvolvido quanto o outro.

É possível estabelecer algumas aproximações entre a teoria da dependência e o pensamiento decolonial. A oposição estrutural entre "centro" e "periferia", que forma um dos princípios de análise da teoria da dependência, poderia ser traduzida, no vocabulário do pensamiento decolonial, no par de termos "modernidade" e "colonialidade". E, como é sabido, a própria definição do conceito de sistema-mundo moderno de Immanuel Wallerstein e, por conseguinte, a formulação do conceito de sistema-mundo moderno-colonial de Quijano (2005), sofreram influências da teoria da dependência (Restrepo e Rojas, 2010).

Entretanto, para além dos aportes levantados pela teoria da dependência, centrados, sobretudo, em análises de dimensões econômicas e políticas, a corrente teórica do pensamiento decolonial busca problematizar as estruturas de dominação herdadas do período colonial, considerando também as dimensões simbólicas e subjetivas deste processo.

É neste sentido que autores como Quijano (2005) e Mignolo (2003) enfatizam o processo de subalternização de saberes, epistemologias e representações de mundo, forjados a partir da constituição do sistemamundo moderno-colonial, e buscam problematizar o imaginário de mundo profundamente eurocêntrico que nos constitui. Desse modo, ainda, veremos ao longo deste artigo, que a diferenciação entre colonialismo e colonialidade, bem como o conceito de raça, possuem importante centralidade nas argumentações de seus autores. 
Assim, a opção pelo trabalho com a linha teórica do pensamiento decolonial justifica-se também pelo fato de esta articular em sua análise tanto as dimensões materiais como as simbólicas e as mais subjetivas, conformadoras da realidade. Dessa forma, ela pode oferecer instrumentos relevantes para a problematização de conceitos geográficos tão fortemente arraigados e naturalizados em nosso imaginário de mundo, ao ponto de pouco nos perguntamos sobre sua origem e conteúdo histórico e político.

\section{Uma categoria de análise?}

Normalmente, assumimos de modo tão naturalizado as designações e recortes geográficos das regiões que visualizamos em mapas ou que utilizamos como referência de pertencimento e localização, que dificilmente nos questionamos sobre os processos de regionalização que instituíram esses nomes e desenhos cartográficos.

A subdivisão do mundo entre os continentes que hoje conhecemos pelas designações de Ásia, Oceania, África, América e Europa, tomada como uma realidade incontestada, oculta a estrutura geopolítica que esta regionalização impõe, bem como o longo processo histórico que a formou (Mignolo, 2007).

Em grande medida, é recorrente o uso do conceito de América Latina como sendo a indicação de um recorte espacial dentro da subdivisão do planeta em grandes áreas. No intuito de situar ou localizar um determinado fenômeno, quando escutamos ou fazemos alguma alusão ao termo América Latina, imediatamente recorremos às imagens com as quais aprendemos a dividir o mundo e identificar suas diferentes regiões geográficas. Nesse caso, tomamos a expressão 'América Latina' como referida a um objeto ou a uma realidade empírica claramente existente e percebida.

Essa forma de conceber o conceito de América Latina acaba por reificar o que é um recorte geográfico e instrumento de análise, este sendo a própria forma como os fatos e a realidade são e se organizam. De maneira acrítica, portanto, toma-se uma construção intelectual para interpretar a realidade,, naturalizando-a, transformando-a em coisa objetiva.

Esse processo de reificação, contudo, produz não somente certa confusão entre representação e realidade. Ele oculta que, ao longo de sua história, o conceito de América Latina foi formulado e acionado como estratégia de controle e demarcação de formas particulares de se 
compreender e dizer o que é mundo. Configurando-se, portanto, mais como recurso de práticas sociais do que como simples forma de analisar e identificar um recorte de área específico.

\section{A visão cristã tripartida de mundo}

Houve tempo em que a região que hoje conhecemos pelo nome de América Latina era reconhecida pelos povos que aqui viviam a partir de outras designações. Abya-Yala, Tawantinsuyu e Anahuac são algumas delas. Antes de 1492, América não figurava em nenhum mapa ou representação do mundo, pois até esse momento a ideia de um quarto continente ainda não havia surgido: "El territorio existía y los pobladores también, por supuesto, pero ellos daban su propio nombre al lugar donde vivían [...]" (Mignolo, 2007, p. 28).

Antes de 1492, a cosmologia cristã dividia o mundo em apenas três continentes: Ásia, África e Europa. Nenhuma outra cosmologia, entre as demais civilizações daquele período histórico - como a chinesa, a indiana, a inca, a japonesa ou a árabe-islâmica - ,regionalizava o mundo desta maneira. Apenas os cristãos do Ocidente partilhavam desse imaginário, uma visão tripartida do mundo expressa no mapa cristão do $\mathrm{T}$ em $\mathrm{O}$ e referenciada nos três filhos de Noé: Ásia representando Sem; África, Cam e; Europa, Jafé (Mignolo, 2003; 2007).

A correlação entre os filhos de Noé e cada um dos três continentes, até então conhecidos pela cosmologia cristã, surge de influências das idéias de Santo Agostinho. Como relatado em seu livro A Cidade de Deus, Cam é o amaldiçoado, o herege, o filho que pecou contra o pai e teve seus descendentes condenados a serem servos de seus irmãos. Sem e Jafé, ao contrário, foram os filhos abençoados por Noé. A Jafé foi designada a benção do crescimento, do engrandecimento, e este reinaria, então, sobre os outros irmãos (Mignolo, 2007, 2003).

Apesar do conceito de raça, como hoje o concebemos, ter sua origem, no século XVIII, implícita à narrativa cristã sobre o repovoamento da Terra pelos descendentes de Jafé, Sem e Cam depois do Dilúvio, encontra-se um sentido de superioridade e inferioridade na classificação dos povos segundo os continentes, sentido que se faz expresso no mapa do T em O (Mignolo, 2007).

Desta divisão tripartida de mundo, referenciada nos filhos de Noé e marcada por um sentido de superioridade e inferioridade entre os continentes, surgirá a base de elaboração dos mapas-múndi dos séculos XVI e XVII (Mignolo, 2007).

É neste quadro de categorização e hierarquização dos continentes, que América será incorporada como quarto elemento da cosmologia cristã 
tripartida. Com os mapas do mundo traçados por Gerardus Mercator, em 1542, e Abraham Ortelius, em 1575 - primeiros mapas do mundo moderno-colonial -, pela primeira vez na história da humanidade o mundo aparecerá dividido nos quatro principais continentes que conhecemos hoje.

A partir desse momento, a crença em uma configuração do planeta que corresponde a uma divisão real e natural em quatro continentes, ganha extraordinária força e alcance (Mignolo, 2007). Como consequência, outras conceitualizações espaciais para esta região denominada, agora, como América, são silenciadas: Tawantisuyu, Anáhuac e Abya-Yala desaparecem.

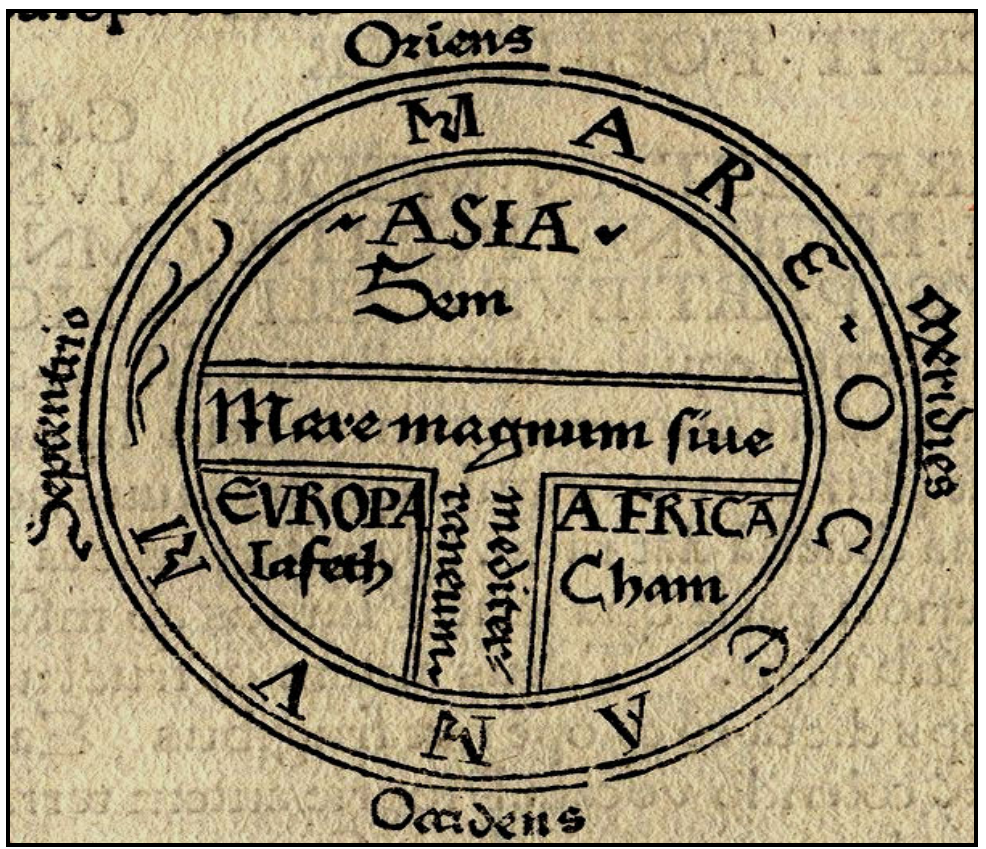

Figura 1: Mapa cristão do T/O: alusão à Europa como o lar dos descendentes de Jafé, a África sendo dos descendentes de Cam e a Ásia lar dos descendentes de Sem. O "T" representa o Mar Mediterrâneo dividindo três contimentes: Ásia, Àfrica e Europa, sendo o "O" um Oceano circundante.

O conceito de América surge, assim, a partir de uma visão de mundo provinciana e particular, específica à cosmologia cristã. Neste sentido, "não é possível compreender a idéia de América sem a existência de uma divisão tripartida do mundo anterior ao descobrimento/invenção do 
continente, com suas correspondentes conotações geopolíticas cristãs" (Mignolo, 2007:33; 48).

O conceito de América e, posteriormente, América Latina, é uma construção semântica com implicações políticas, econômicas, epistêmicas e éticas que surgiu e se impôs, em detrimento de conceitualizações e denominações originárias deste mesmo continente.

O termo América, como sabemos, é uma homenagem a Américo Vespúcio, comerciante e navegador italiano que observou o fato de que as terras encontradas por Cristovão Colombo anos antes, em verdade, não se tratavam das Índias (Ocidentais), mas de um "Novo" Mundo.

A homenagem surge em 1507, por sugestão do cosmógrafo alemão Martin Waldseemüller, membro do destacado Ginásio Vosgense, localizado na cidade de Saint Die, em Lorena, na França. Para que estivesse acomodado ao imaginário de mundo do período, o termo recebe uma flexão de gênero gramatical para o feminino, combinando, então, com as designações Ásia e África (Mignolo, 2003; 2007).

Mas não apenas o conceito América é inserido como sobreposição a outras designações e representações de mundo que os habitantes originários atribuíam aos seus espaços de vida. Com o advento da conquista e a incorporação de um quarto continente ao quadro de mundo cristão, "Índias Ocidentais" e "Novo Mundo", duas outras formas como também foram batizadas as novas possessões coloniais de Espanha e Portugal, são inseridas no imaginário de mundo europeu e coexistem com a designação de América (Mignolo, 2003; 2007).

O conceito de "Novo Mundo", ao implicar um sentido de anterioridade aos continentes europeu, africano e asiático, em relação à América, silenciou a contemporaneidade histórica desta, ignorando sua existência simultânea às demais regiões (Mignolo, 2007).

Nesse sentido, poderíamos dizer que, com a invenção do conceito de América, prevalece uma conceitualização espacial que Massey (2004) identifica como "conceber o espaço em termos temporais" (Massey, 2004:15). Muitas das expressões utilizadas para qualificar diferentes espaços geográficos - como "avançado", "atrasado", "moderno", "em desenvolvimento" - apontam para uma compreensão das diferenças espaciais a partir de marcos temporais sequenciais.

Configura-se, desse modo, como uma maneira de conceber as diferenças geográficas em termos de sequência histórica, ou seja, da posição que uma região do planeta ocupa na evolução linear da história 
dita mundial. Nessa perspectiva, prevalece uma compreensão espacial que subtrai a contemporaneidade do "Outro", negando-lhe sua alteridade e impondo uma história de narrativa única (Massey, 2004). Como afirma Mignolo: "América sempre foi concebida como um continente que não coexistia com os outros três, mas que apareceu mais tarde na história do planeta, razão pela qual se lhe dá o nome de 'Novo Mundo.' " (Mignolo, 2007, p. 51).

O conceito de "Índias Ocidentais", por sua vez, reproduz um sentido de centralidade ao continente europeu no cenário mundial. Até 1492, o centro do mundo cristão era localizado em Jerusalém e, Europa, portanto, encontrava-se ao ocidente, a oeste desse centro. Com o surgimento das Índias Ocidentais, no imaginário de mundo cristão, América passa a configurar o extremo ocidente deste cenário, deslocando Europa - e o Ocidente, portanto - para o centro do quadro (Mignolo, 2007).

Por um lado, o termo "Índias Ocidentais" passa a localizar o Ocidente como centro, locus privilegiado de enunciação, região geográfica a partir de onde se tem o poder e o privilégio de classificar e dizer o que é e como deve ser o mundo. Por outro, faz da região geográfica designada como América, extensão e expansão da Europa, uma exterioridade que lhe pertence, o extremo ocidente que faz parte, agora, das possessões de Jafé, filho de Noé, que tinha como futuro e destino o fôlego, o engrandecimento e a expansão. Como afirma Walter Mignolo: "a partir daí, as Índias Ocidentais definiram os confins do Ocidente e, se bem fossem parte de sua periferia, pertenciam ao Ocidente de todos os modos" (Mignolo, 2007, p. $60)$.

Durante o século XVI, quando a América foi concebida como tal, não pela coroa espanhola, mas por intelectuais do Norte - Itália e França ,ficava implícito que ela não era nem a terra de Sem - o Oriente -, nem a terra de Cam, a África, mas a extensão da terra de Jafé. Não havia nenhuma outra razão senão a distribuição geopolítica do planeta, implementada pelo mapa T/O cristão, para percebê-lo dividido em quatro continentes; e o único lugar para a "América" no mapa T/O cristão era o domínio de Jafé, isto é, o Oeste (Ocidente) (Mignolo, 2003, pp. 91-92).

Nessa perspectiva, a própria narrativa do "descobrimento" é parte também de uma visão de mundo restrita ao universo cristão europeu e exemplo de um discurso que posiciona a Europa como centro do mundo, descartando, mais uma vez, a contemporaneidade e coexistência dos povos que habitavam Tawantisuyu, Anáhuac e Abya-Yala, como nos alerta Mignolo: "América nunca foi um continente que houvesse que descobrir, e sim uma invenção forjada durante o processo da história colonial européia 
e da consolidação e expansão das idéias e instituições ocidentais" (Mignolo, 2007, pp. 28-29). Portanto, houve uma invenção eurocêntrica da América, que encobriu seus povos originários, e não descobrimento.

\section{América e formação do sistema-mundo moderno-colonial}

A globalização que vivemos nos dias de hoje é o auge de um processo iniciado há mais de 500 anos com a conquista da América, o desenvolvimento do sistema capitalista e a formação de um novo padrão de poder mundial centrado na Europa. Nesse processo, a América foi o ato constitutivo, o ponto de partida e condição de possibilidade para a formação do que viria a ser o sistema-mundo moderno, um novo padrão de poder com vocação mundial (Quijano, 2005).

De acordo com Dussel (2005), no século XIII, a região geográfica, que hoje conhecemos como Europa, manteve papel periférico dentro do contexto histórico do continente euro-afro-asiático. Até o século $\mathrm{XV}$, a Europa formava um local secundário e isolado em relação ao "mundo turco muçulmano, que dominava politicamente do Marrocos até o Egito, a Mesopotâmia, o Império Mongol do Norte da Índia, os reinos mercantis de Málaga, até a ilha de Mindanao, nas Filipinas" (Dussel, 2005, p. 58).

No quadro de mundo dos séculos XIII e XIV, a ordem mundial então vigente encontrava-se organizada pelo predomínio de oito circuitos comerciais que interligavam centros mercantis localizados na Europa, África e Ásia, estendendo-se desde Pequim até Gênova, extremidades desta rede. Nesse antigo cenário, a China ocupava posição dominante e a Europa, o lugar mais marginal (Mignolo, 2003; 2005; 2007).

Nesse mapa de época, coexistiam ainda dois outros importantes circuitos comerciais: Anáhuac e Tawantinsuyu. Estes, localizados no que apenas posteriormente viria a ser designado como América, encontravamse, até esse momento, desligados dos circuitos mercantis europeus, asiáticos e africanos, bem como inexistentes no imaginário de mundo destas civilizações. E o que nos evidencia o mapa traçado por Janet L. Abu-Lughod (Ábu-Lughod apud Mignolo 2003; 2005). 


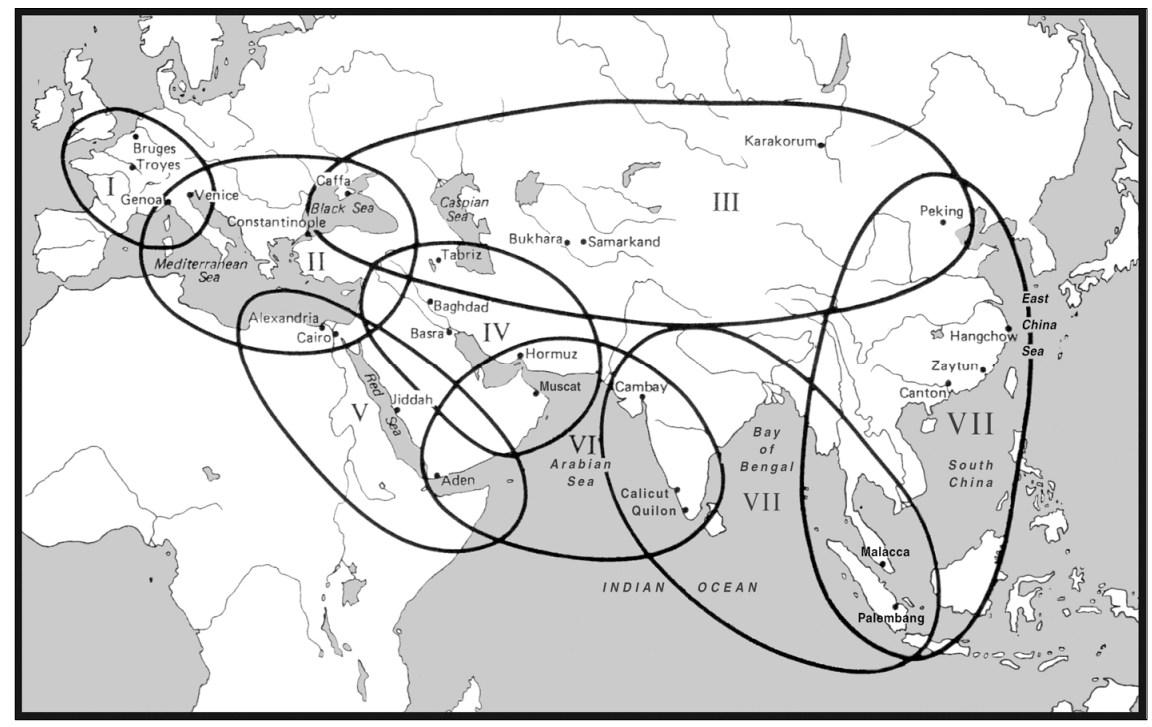

FIGURA 2: Os oito circuitos comerciais predominantes entre os anos de 1250 e 1350, segundo Janet L. Abu-Lughod. Observemos que Anahuác e Tawantinsuiu, assim como o oceano Atlântico, não fazem parte do quadro de mundo da época. Fonte: (MIGNOLO, 2005:76).

Até esse momento, portanto, não se poderia falar em uma história de fato mundial. O que existiam eram "histórias justapostas e isoladas: a romana, persa, do reino dos hindus, de Sião, da China, do mundo mesoamericano ou Inca na América, etc.” (Dussel, 2005, p. 59).

A partir do século XVI, no entanto, esse quadro começa a sofrer grande transformação. A emergência de um novo circuito comercial, inaugurado com o "descobrimento" e o processo de colonização da América, passa a estabelecer uma ligação entre o Mediterrâneo e o Atlântico, conectando, pela primeira vez na história, todos os circuitos mundiais até então existentes e lançando os alicerces do que viria a ser o moderno sistema-mundo (Mignolo, 2003; 2005; 2007). 
Acompanhando a emergência do circuito comercial do Atlântico, estrutura-se, ainda, uma profunda transformação no imaginário global das civilizações daquele período. Pela primeira vez na História, uma visão total do que seria o planeta torna-se disponível. E, também como fato inédito, a Europa passa a ocupar um lugar central nesse imaginário de mundo (Mignolo, 2003).

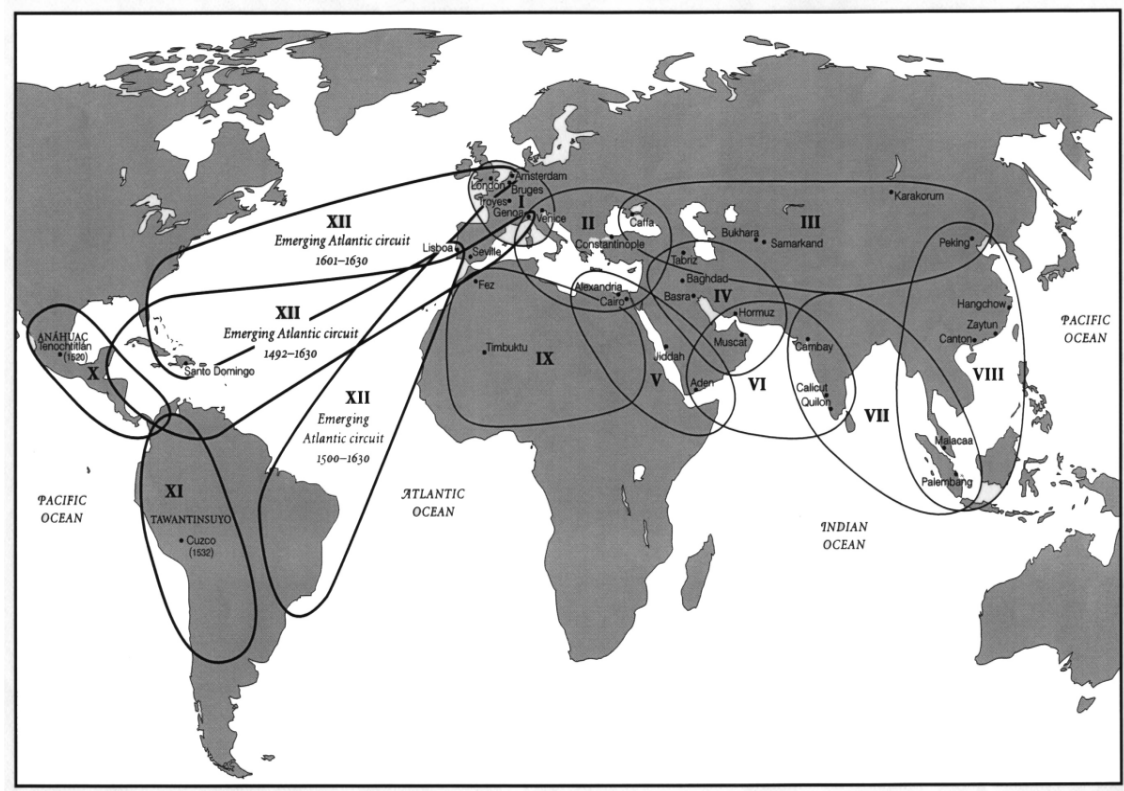

Figura 3: A partir do séc. XV, o surgimento do circuito comercial do Atlântico conecta Anáhuac e Tawantinsuiu aos circuitos mercantis do Mediterrâneo. América e o oceano Atlântico são incorporados ao imaginário de mundo europeu, pela primeira vez na história, uma visão global do que seria o planeta torna-se disponível (Fonte: MIGNOLO, 2005:77).

É nesse cenário de grandes mudanças que são lançadas as bases da formação do sistema-mundial moderno. Os circuitos comerciais de todas as regiões do planeta estão, pela primeira vez, conectados e uma nova concepção global do mundo passa a estar disponível. Um novo padrão de poder mundial começa a constituir-se centrado na Europa, e não mais na China.

Nesse desenho de forças que se inaugura, a conquista da América exerce um papel-chave, motivo pelo qual Quijano e Wallerstein (apud Mignolo, 2003:84), em já conhecida argumentação, afirmam que a constituição da América enquanto uma região sob controle europeu teve 
importância decisiva na formação do sistema-mundial moderno e na própria formação da economia capitalista. Sem América, nos dizem os autores, não haveria sistema capitalista mundial.

Desse ponto de vista, ao contrário do que estamos acostumados a imaginar, a América exerceu um papel decisivo no processo de formação do sistema-mundo moderno. É apenas a partir do surgimento da América que a Europa passa a afirmar-se como centro geopolítico do mundo. Sem o ouro e a prata da América, sem a ocupação de suas terras para o plantio da cana-de-açúcar, do café, do tabaco e tantas outras especiarias, sem a exploração do trabalho indígena e escravo, a Europa não se faria nem moderna, nem centro do mundo (Porto-Gonçalves, 2003).

Observa-se, assim, que o colonialismo, relação estruturada em torno do controle político e econômico metrópole-colônia, encontra-se na base do novo padrão de poder que se inaugura. Segundo Antonio Carlos Robert de Moraes, "a colonização envolve conquista, e esta se objetivava na submissão das populações encontradas, na apropriação dos lugares, e na submissão dos poderes eventualmente defrontados" (Moraes, 2008, p. 65).

Dessa forma, é no violento processo de dominação e exploração da América que localiza-se um dos principais fatores da profunda transformação que o cenário mundial sofre em finais do século XV e início do século XVI: extermínio de populações inteiras, a escravidão, a servidão, a (des) possessão de terras, a exploração das riquezas naturais, encontramse nos fundamentos das relações sociais e de poder que instituem América, Europa e o sistema-mundo moderno que se ergue.

No entanto, como nos recorda Franz Fanon (1965), não é possível entender o colonialismo apenas a partir dos aparatos militares e administrativos que engendram a dominação física de algumas populações e territórios. Ele deve ser entendido, também, a partir dos discursos de inferiorização dos colonizados. Inferiorização imposta pelo colonizador, incorporada e reproduzida nos próprios referenciais culturais do colonizado. Logicamente, nos diz Fanon, "não é possível submeter à servidão aos homens sem inferiorizá-los parte por parte." Nesta acepção, o autor nos evidencia o profundo vínculo entre colonialismo e racismo, pois "o racismo não é mais que a explicação emocional, afetiva, algumas vezes intelectual, desta inferiorização” (Fanon, 1965, p. 48). 


\section{América e a Colonialidade do Poder}

Quijano (2000) destaca que as relações sociais e de poder, que erguem o sistema-mundo moderno e produzem a América enquanto território sob domínio europeu, se estruturam em torno de dois eixos fundamentais: a classificação da população mundial a partir da idéia de raça e a articulação de todas as formas de controle do trabalho.

Considerado em seu sentido mais amplo, os processos de classificação social encontram-se intimamente relacionados com a questão do poder na sociedade, pois se referem aos lugares e às posições que indivíduos e grupos sociais ocupam (ou devem ocupar) no controle das dimensões básicas da existência social.

As classificações sociais não são atributos naturais ou biológicos já dados pela realidade, mas construções históricas que, erguidas nas relações sociais, naturalizam-se no próprio processo de reprodução e manutenção de um determinado padrão de poder. Não determinam os indivíduos e grupos sociais, mas os fazem na mesma medida em que por eles são refeitas (Quijano, 2000). Considerando essa acepção mais abrangente, é que, em uma dimensão mais restrita, o autor irá compreender a noção de classificação racial da população mundial.

A partir, então, da conquista da América, continua Quijano, trabalho, raça e gênero articulam-se como os três eixos principais de classificação social do novo padrão mundial de poder. As diferenças fenotípicas, como por exemplo, a cor da pele, a forma e cor do cabelo, dos olhos, do nariz, começam a ser utilizadas no processo de colonização como forma de diferenciar conquistadores e conquistados, europeus e não-europeus, estabelecendo, assim, uma relação de superioridade e inferioridade pautada nas distintas estruturas biológicas de cada grupo social e criando supostas gradações de seres humanos.

Assim, são criadas identidades sociais até então inexistentes, como índio, negro e mestiço. Designações que, como sabemos, homogeneizaram, em um único termo, uma imensa diversidade de povos, como é o caso das culturas Inca, Maia, Asteca, Zapoteca, Guarani, Quéchua, Aimara, Banto entre tantas outras que tiveram suas diferenças reduzidas a uma única categoria social (Porto-Gonçalves, 2003).

É com a invenção eurocêntrica da América, portanto, que surge o conceito de raça; maneira de legitimar as relações de dominação impostas pela conquista e estabelecer o controle europeu sobre todas as formas de subjetividade, cultura, e produção do conhecimento (Quijano, 2005). 
Nenhum dos habitantes do continente, que conhecemos como África, jamais se chamou de negro, assim como os europeus, até então, não haviam se chamado de branco.

A distinção/discriminação das pessoas com a noção pseudo-científica de raça é parte de um sistema de poder mundial que prevalece até hoje. Assim, embora a raça não exista como conceito científico, o racismo existe como fenômeno social real. Os negros e os povos originários que o digam e, costumam dizer, com a força de um conhecimento, que vem acompanhado de sentimento, na medida em que o racismo não é simplesmente uma idéia, mas prática cotidianamente sofrida.

Contudo, é importante destacar que, enquanto matriz classificatória, o racismo é mais amplo que a categorização do ser humano a partir de suas características físicas e se desdobra em todos os planos da existência social, como a religião, a língua e as classificações geopolíticas do mundo. Como afirma Mignolo: "a categorização racial não consiste simplesmente em dizer 'és negro ou índio, portanto, és inferior', mas sim dizer 'não és como eu, portanto, és inferior"” (Mignolo, 2007:41-43).

No processo de constituição da América, afirma Quijano (2005), pela primeira vez na história, todas as formas de controle e de exploração do trabalho conhecidas passam a estar articuladas em torno da relação capitalsalário e do mercado mundial. A escravidão, a servidão, a pequena produção mercantil, a reciprocidade e o trabalho assalariado passam a estar articuladas em função do capital, constituindo o conjunto de relações de produção que formam o sistema capitalista emergente.

Aos poucos, as identidades sociais inventadas pela classificação racial da população mundial associam-se ao lugar que estes grupos passam a ocupar na divisão do trabalho. Os índios, portanto, passam a estar associados à estrutura social da servidão, os negros, à escravidão e o europeu, ao trabalho assalariado. Assim, o trabalho não-pago passa a estar vinculado às "raças" dominadas, posicionadas como inferiores, e o trabalho assalariado, aos brancos, aos europeus (Quijano, 2005).

Nesse mesmo processo, os territórios e organizações políticas de base territorial foram sendo classificados de acordo com a suposta posição "racial" em que seus habitantes eram situados. Dessa classificação estruturou-se a articulação e a assimetria de poder entre Europa, América, África e Ásia, fato que facilitou a naturalização do controle europeu sobre os outros territórios e fez estas identidades geográficas vigorarem no imaginário social das pessoas até os dias de hoje mais como resultado de 
uma expressão da natureza, do que da história de poder do planeta (Quijano, 2000)..

A partir da idéia de raça, portanto, instituem-se um conjunto de relações de poder que hierarquizam os lugares e suas gentes, classificandoos de acordo com um suposto grau de evolução e desenvolvimento societário: "num continuum linear que vai da natureza à cultura, ou melhor, da América e da África, onde estão os povos primitivos mais próximos da natureza, à Europa, onde está a cultura, a civilização" (Porto-Gonçalves, 2002, p. 218). Logo se observa, portanto, que os parâmetros de modelo civilizatório e de classificação das populações são dados por aqueles que estão em uma posição de poder para decidir onde uma cultura se localiza em relação aos próprios referenciais de mundo de quem as classificou (Mignolo, 2007).

Essa idéia de raça, associada à classificação da população mundial, surge, por exemplo, nos escritos de Bartolomeu de Las Casas que datam do século XVI. Preocupado em definir em que estágio de desenvolvimento societário estariam inseridos os índios do "Novo Mundo", Las Casas estabelece diferentes níveis de desenvolvimento humano, tendo como referência seu próprio universo cultural e a distância ou proximidade de outros povos e culturas em relação a este modelo. Assim, cria e identifica quatro diferentes classes de "bárbaros", baseando-se em critérios como o domínio da escrita alfabética, o sistema de governabilidade e a língua de um povo (Mignolo, 2007).

Nesses termos, alguns povos e grupos sociais acabam sendo identificados fora da categoria de seres humanos, são descartáveis, prescindíveis e não formam parte da história, ou são rotulados como seres humanos de segunda classe, como no caso dos índios e dos escravos africanos (Mignolo, 2007). Para Maldonado-Torres (2007), são povos e grupos sociais sob permanente suspeita e dúvida a respeito de sua qualidade de humanos.

A este padrão de controle, hierarquização e classificação da população mundial, que afeta todas as dimensões da existência social e que tem no conceito de raça seu eixo estruturante, Quijano (2003) denominou colonialidade do poder. Para o autor, a colonialidade não se esgota no colonialismo, forma de dominação político-econômica e jurídicoadministrativa das metrópoles europeias sobre suas colônias, expressa, mais que isto, um conjunto de relações de poder mais profundo e duradouro que, mesmo com o fim do colonialismo, se mantém arraigado nos esquemas culturais e de pensamento dominantes, legitimando e naturalizando as posições assimétricas em que formas de trabalho, 
populações, subjetividades, conhecimentos e territórios, são localizadas no mundo contemporâneo (Quijano, 2000; 2005; Escobar, 2003; CastroGómez e Grosfoguel, 2007; e Maldonado-Torres, 2007).

Dessa forma, o sistema mundo moderno que se constitui a partir da conquista da América, em 1492, - e às custas dessa - configura-se, em verdade, como um sistema mundial moderno-colonial, expressão criada com o objetivo de designar a contraface colonial constituinte da modernidade e do sistema-mundo moderno (Quijano, 2005). Omitir o lado colonial do sistema mundo é olvidarmos o caráter colonial da modernidade. Quando se pensa em modernizar a Amazônia, por exemplo, a idéia de colonizá-la está subjacente.

Usualmente, as interpretações predominantes sobre a modernidade demarcam seu início e consolidação a partir de acontecimentos intraeuropeus, como a Reforma, o Iluminismo, a Revolução Francesa e a Revolução Industrial, fenômenos situados nos séculos XVII e XVIII e em países da Europa do Norte, sobretudo, Inglaterra, Alemanha e França. Entretanto, na perspectiva de autores como Enrique Dussel, tais eventos históricos são precedidos por uma primeira modernidade, situada nos séculos XV e XVI, em torno da formação do sistema-mundo e da conquista e colonização da América, processos inaugurados por Espanha e Portugal. Nestes termos, Enrique Dussel afirmará que o ego cogito moderno foi precedido pelo ego conquiro (eu conquisto), protagonizado pelo colonizador europeu dos séculos XV e XVI (Dussel, 2005; Escobar, 2003; Maldonado-Torres, 2007). América é compreendida, assim, como parte constitutiva da modernidade, uma exterioridade que lhe é interior.

Neste sentido, não se deve compreender a modernidade como um fenômeno essencialmente europeu, mas como um processo inserido na própria constituição do sistema-mundo moderno-colonial e na assimétrica relação que Europa instituiu com outras regiões do planeta. É o que nos indica Porto-Gonçalves (2006), quando sinaliza que "o açúcar, principal mercadoria manufaturada nos séculos XVI e XVII, era produzido nos mais modernos engenhos de produção até então construídos e que não estavam na Europa, mas, sim, no Brasil, em Cuba, no Haiti. Somos modernos há 500 anos", conclui o autor (Porto-Gonçalves, 2006:153). Ou, ainda, como afirma Doreen Massey (2004), sendo o espaço um produto de interrelações, "a 'verdadeira' xícara de chá inglesa dependeu, para seu aparecimento, de um colonialismo que se estendia da escravidão do açúcar no Caribe à Companhia das Índias Orientais e às guerras do ópio na China" (Massey, 2004:17). O genocídio e a escravidão, a servidão e a violência, a 
opressão e o saqueio são, portanto, parte constitutiva da modernidade, seu lado oculto, sua colonialidade.

Considerar o sistema mundo como moderno-colonial é deixar que o espaço fale, haja vista que é o espaço-mundo como um todo que se conforma, e não o mundo visto como se fosse estágios distintos da Europa e, assim, um evolucionismo em que os lugares e as regiões do mundo são silenciados.

\section{A "latinidade" da América Latina}

O conceito de América Latina guarda uma forte dimensão política e estratégica. Este conteúdo político, mormente caracterizado por tom racial e pejorativo, produtor de formas de desrespeito e de inferiorização do Outro, apesar de aparentemente ausente do sentido como o conceito é empregado nos dias de hoje, não deixa de constituí-lo e, portanto, de ser também um fator de ação no mundo.

A concepção de uma América Latina surge de uma apropriação criativa que intelectuais de origem hispânica, nascidos na América, fazem da divisão entre Latinos e Anglo-Saxões que marcou os conflitos entre as potências do continente europeu no século XIX e, particularmente, os conflitos imperialistas entre França e Estados Unidos no cenário das revoluções de independências, ocorridas ao longo do século XIX no continente americano. Como destaca Alain Rouquié (1992), o uso da expressão "latina" surge na França bonapartista de Napoleão III como estratégia geopolítica frente ao projeto expansionista dos EUA, baseado na Doutrina Monroe (1823). Não se encontram registros sobre o uso do termo América Latina antes desse período.

O conceito de América Latina derivou da noção de latinidade, expressão elaborada na França como forma de rivalizar, com Inglaterra e Alemanha, a hegemonia na Europa (Mignolo, 2007). Michel Chevalier (1806-1879), intelectual francês de grande influência na Europa, foi uma importante figura política no processo de afirmação do conceito de latinidade e um dos grandes ideólogos da burguesia em ascensão na França. Em 1836, Chevalier publicou o livro Cartas sobre América do Norte, trabalho que relatava sua visita aos Estados Unidos em 1833. Segundo Chevalier, a Europa seria formada por países de origem latina e países de origem teutônica. Os países latinos, localizados ao sul, representados por Portugal, Espanha, Itália e França, seriam de formação católica. Os países teutônicos, ao norte, incluindo Inglaterra, seriam de 
formação protestante. Este par de oposições entre católicos (latinos) e protestantes (Anglo-Saxões) marcaria a geopolítica européia e produziria repercussões na América (Mignolo, 2007).

O termo latim, lembra-nos Feres Júnior (2005), originalmente referese à língua falada no Lácio, região do centro-oeste da Itália, incorporada a Roma no século $3^{\circ}$ a.c. A partir do processo de expansão do Império Romano, a língua latina foi sendo imposta aos povos europeus que iam sendo conquistados e, o longo período de dominação e ocupação territorial, deu origem às línguas neolatinas. O termo Anglo-Saxão, por sua vez, surge do processo de invasão que os povos anglos, saxões e juntos realizaram na Inglaterra após a saída das legiões romanas. A origem linguística desses povos remete-se ao dialeto germânico/teutônico, língua que também foi imposta às populações conquistadas. Essas duas principais matrizes de formação da Europa moderna serão evocadas como discurso geopolítico na disputa entre os países europeus em ascensão no século XIX.

A partir da segunda metade do século XIX, é forjada e estabelecida uma nova configuração de forças no cenário mundial: Portugal e Espanha já não possuíam o mesmo vigor e liderança dos séculos XV e XVI e estavam em decadência. França e Inglaterra se consolidavam como as duas principais potências imperiais da Europa e os Estados Unidos intensificavam seus projetos expansionistas expressos, sobretudo, na conhecida doutrina do Destino Manifesto (Mignolo, 2003).

Nesse contexto, segundo Mignolo (2007), o conceito de América Latina surge associado à noção de "latinidade", forma encontrada pelos franceses de diferenciarem-se da Europa anglo-saxônica (Inglaterra) e demarcarem o interesse dos países europeus de origem latina sobre a América, ao mesmo tempo em que confrontavam a franca expansão dos Estados Unidos. A partir de então, a designação "latina", explica Mignolo: "foi introduzida pela intelectualidade política francesa e usada na época para traçar as fronteiras, tanto na Europa, como nas Américas, entre anglosaxônicos e latinos" (Mignolo, 2003:59).

Feres Júnior (2005) nos traz mais alguns detalhes sobre o contexto político em que a expressão América Latina foi criada. Segundo o autor, na França de Napoleão III (1852-1870), florescia o panlatinismo, doutrina que apregoava a unidade dos povos de raça latina sob liderança e vanguarda francesa. Assim, na concepção de ideólogos, como Michael Chevalier, cabia à França a responsabilidade de reconduzir, frente aos povos germânicos e anglo-saxões, as nações latinas ao lugar de principais protagonistas da história da civilização humana (Feres Júnior, 2005). 
Nesse período, fervilhava, no continente europeu, o movimento filosófico e literário do romantismo, ambiente cultural que favoreceu o surgimento de ideologias nacionalistas a partir da concepção romântica de que a unidade política do Estado seria precedida pela unidade linguística, racial e consuetudinária do povo. Nestes termos, raça, língua e costumes passavam a ser evocados para justificar o controle político de determinados grupos sobre outros. Não por acaso, o adjetivo latine foi recorrentemente utilizado no discurso do panlatinismo em associação com o termo race, race latine, possível embrião de uma concepção de América Latina (Feres Júnior, 2005).

É nesse cenário, de apelo nacionalista, que o panlatinismo de Chevalier e Napoleão III é arquitetado, configurando-se, em verdade, como um projeto imperialista francês que incluía a submissão das ex-colônias ibéricas do continente americano. Todavia, se a expressão race latine surge com o panlatinismo, o conceito de América Latina propriamente dito é formulado pela primeira vez por José Maria Torres de Caicedo, jornalista e poeta colombiano (Feres Júnior, 2005).

Caicedo viveu praticamente toda sua vida adulta em Paris, mas conservava vínculos com sua terra natal. Diante do expansionismo territorial dos EUA, defendeu a formação de uma confederação de repúblicas latino-americanas e a base dessa união estaria na herança latina comum a esses povos. No poema Las dos Americas, de Caicedo, publicado no ano de 1856, em Veneza, encontra-se o primeiro registro do uso da expressão América Latina.

\footnotetext{
Mas aislados se encuentran, desunidos,

Esos pueblos nacidos para aliarse:

La unión es su deber, su ley amarse:

Igual origen tienen y misión;

La raza de la América latina,

$\mathrm{Al}$ frente tiene la sajona raza,

Enemiga mortal que ya amenaza

Su libertad destruir y su pendón.
}

As preocupações de Caicedo, no entanto, pouco tinham relação com os interesses domésticos franceses. Seus escritos eram endereçados às comunidades de língua espanhola na Europa e na América e seus projetos de articulação política não explicitavam qualquer participação francesa. Foi nestes termos que o poeta criou a Sociedad Latinoamericana Cientifico-

${ }^{1}$ Trecho do poema Las dos Américas de José Maria Torres Caicedo,1856. 
Literaria, em 1868, e a Sociedad de la Unión Latinoamericana, em 1879, projetos que logo fracassaram (FERES JÚNIOR, 2005). Assim, a partir de um debate colocado em outro contexto geopolítico, Caicedo produz uma apropriação criativa da latinidade ao imprimir um sentido anti-imperialista à expressão, desvinculado-a dos interesses napoleônicos.

Segundo Feres Júnior (2005), tanto em sua versão francesa, como em sua versão espanhola, o termo América Latina foi utilizado como discurso de combate à expansão dos Estados Unidos. A distinção entre Latino e Anglo-Saxão, constituía o caráter essencial dos projetos do autor. No caso francês, no entanto, essa diferenciação foi fortemente articulada a partir do conceito de raça, e o termo América Latina expressava, não apenas uma contraposição ao expansionismo norte-americano, mas delineava, também, as ambiciosas pretensões imperialistas da França monárquica (Feres Júnior, 2005).

Por outro lado, na perspectiva dos países da Europa do Norte e, posteriormente, dos Estados Unidos, esses termos serviram para demarcar justamente o contrário, ou seja, a idéia de uma superioridade da "raça anglo-saxã".

No século XVI, em razão das disputas religiosas e do grande poder que a Coroa Espanhola possuía na Europa de então, ampliando seus domínios territoriais e inspirando terror com suas forças armadas, forjou-se na Grã-Bretanha e em muitos países europeus, um forte sentimento antiespanhol, fato que tornou comum, na língua inglesa, expressões e referências pejorativas a tudo que estivesse de alguma forma relacionado às coisas espanholas. Esse sentimento antiespanhol, conhecido como Lenda Negra, atravessou o Atlântico com os colonos ingleses e vicejou nos Estados Unidos.

Nesse novo contexto, as colônias espanholas da América também passaram a ser objeto de um vigoroso sentimento de desprezo e rejeição, mesmo depois de tornarem-se repúblicas independentes. Formulações como a da incompatibilidade entre a religião católica e governos livres eram comuns entre muitos políticos, inclusive Thomas Jefferson. Adjetivos pejorativos que faziam referência ao estilo de vida, hábitos e costumes dos hispano-americanos, adquiriram força e passaram a estar presentes nos discursos de muitos governantes americanos, sobretudo a partir das políticas expansionistas dos Estados Unidos, como ocorreu no caso da anexação do Texas e da posterior guerra contra o México (1845-1848), período em que adquiriu tons racistas mais evidentes (Feres Júnior, 2005). 
Foi partindo desse contexto, que, na língua americana, criou-se a expressão spanish american e, posteriormente, a expressão Latin America, ambas com fortes traços racistas. Como bem assinala Walter Mignolo, a Lenda Negra foi uma estratégia britânica de domínio da economia do Atlântico, frente ao Império Espanhol, e configurou-se, portanto, como parte de uma disputa entre impérios europeus pelas riquezas do mundo, originando uma diferença imperial que, posteriormente, estaria no cerne da formulação do conceito de América Latina (Mignolo, 2007).

Nos Estados Unidos, a doutrina expansionista do Destino Manifesto (1823) esteve fortemente arraigada nesta concepção pejorativa em relação aos espanhóis. De acordo com Feres Júnior (2005), o Destino Manifesto configurou-se como uma das variantes mais radicais do nacionalismo americano. Toda sua estrutura discursiva foi erguida em torno da premissa de que os americanos anglo-saxões seriam a raça escolhida pela força divina para conduzir a história da humanidade. Assim, com o Destino Manifesto, ganha maior vigor o forte sentimento antiespanhol, presente nos Estados Unidos desde a chegada dos primeiros colonos ingleses.

A doutrina do Destino Manifesto tornou-se, deste modo, um dos principais instrumentos retóricos de legitimação e justificação da guerra contra o México, conflito que resultou na anexação, por parte dos EUA, de uma área do território mexicano, correspondente, hoje, aos estados da Califórnia, Novo México, Utah, Nevada, Arizona e Colorado (Feres Júnior, 2005).

A expressão foi utilizada pela primeira vez por John O'Sullivan, jornalista e ativista político que defendia fervorosamente o expansionismo americano. Suas arguições, assim como a de outros políticos americanos da época, são marcadas por forte conteúdo racista. Nesses discursos, a raça anglófona e teutônica é identificada sempre como superior e, assim, posicionando todos aqueles que a ela não pertencem, como inferiores e subalternos. Nesse contexto, os estadunidenses encontravam justificativa moral para exercer seu expansionismo enfrentando a Espanha monárquica a partir da conquista de suas colônias, como Cuba, Porto Rico, Filipinas e ilhas de Guam (Feres Júnior, 2005), essas últimas no Pacífico e que mais tarde seriam base para a tomada das Filipinas.

Dessa forma, na língua inglesa, o conceito de Latin America abriu, como horizonte de expectativa, formas de desrespeito vinculadas a aspectos culturais, temporais e raciais, uma vez que a raça teutônica é identificada como sendo superior e mais avançada em relação a um "Outro" não-reconhecido, classificado como inferior e atrasado. Localizando o "Outro" espanhol e latino-americano como inferior, o "Eu" 
norte-americano e teutônico relacionalmente afirmava-se como sendo superior.

Tendo essas reflexões em vista, podemos compreender parte das nuances geopolíticas e de formas de desrespeito que envolvem a formulação do conceito de América Latina. A divisão da América em Latina, ao sul, e, Anglo-Saxã, ao norte, como se vê, encontra-se relacionada, em grande medida, às contradições dos desenhos imperiais traçados pelas potências européias sobre as colônias em processo de independência e às resistências que, no interior dessas relações sociais e de poder, foram engendradas a partir da América, que se autodenominaria Latina.

$\mathrm{Na}$ perspectiva francesa, o conceito de América Latina abriu como horizonte de expectativa a legitimação do projeto imperial de Napoleão III frente ao projeto expansionista dos EUA. Pelo lado dos Estados Unidos, houve uma apropriação, no sentido de desqualificação e inferiorização do latino (Espanha) e do latino-americano, como maneira de justificar seu expansionismo. Ambas as visões são erguidas a partir de formas de desrespeito ao Outro, formas de desconsideração em que a dimensão racial surge como forte componente de não-reconhecimento do Outro. Por parte de Caicedo e outros intelectuais de origem hispânica nascidos na América, a expressão ganharia sentido enquanto resistência anti-imperialista. Todavia, resta-nos analisar que outros horizontes de expectativa foram erguidos a partir da apropriação do conceito pela elite criolla iberoamericana.

\section{Elite criolla, "latinidade" e colonialismo interno}

A conquista e a colonização da América produziram formas de falar "fora do lugar", pois, por um lado, romperam os laços tecidos durante séculos entre população indígena e seus mundos de vida e, por outro, colocaram os espanhóis diante de uma realidade completamente nova e distinta da qual estavam habituados (Mignolo 2003, 2007).

Com os processos de independência nas colônias espanholas no século XIX, entretanto, a elite criolla - espanhóis nascidos na América viu-se diante da necessidade de inventar-se a si mesma, desenhando e construindo uma territorialidade que lhe fosse própria. Nesse contexto, adotaram a latinidade como uma designação de pertencimento $\mathrm{e}$ autodeterminação, na qual a França constituía o ideal mirado e almejado de civilização. Desta forma, ao mesmo tempo em que negavam o passado 
colonial espanhol e português, imaginavam-se como pertencendo à modernidade européia. É nestes termos que Mignolo (2007) afirma que "América Latina não é um subcontinente, mas um projeto político das elites criollas_(Mignolo, 2007:82).

Assim, a partir da afirmação de uma unidade continental e de uma identidade regional latino-americana, a elite criolla em ascensão ao mesmo tempo em que marca sua ruptura política com a Europa, mantém sua dependência subjetiva com o modelo de sociedade europeu. Afirmam um processo de negação da Europa, sem negar, no entanto, sua "europeidade", ou seja, os modos de vida, costumes, hábitos, visão de mundo, projetos de sociedade europeus. Conflagram sua ruptura com a metrópole justamente por compreenderem que não são reconhecidos como europeus, mas, em verdade, continuam desejando ser. Compreendem a experiência e condição colonial que os conformam, mas não são capazes de deixar de reproduzi-la. Rompem com o colonialismo, mas não com a colonialidade. Deste modo, afirmam sua "americanidade" sem deixarem de ser europeus e, ao mesmo tempo, demarcam sua diferença em relação aos ameríndios e aos afroamericanos, uma vez que estes, de maneira alguma, teriam como se sentir ou se perceberem europeus, mesmo que marginalmente. Nestes termos, a consciência criolla em relação às suas metrópoles constitui-se como uma contraposição política, mas, do ponto de vista racial, mantém, no âmbito da escala nacional, as mesmas clivagens do sistema-mundo moderno-colonial (Mignolo, 2005).

Assim, o conceito de América Latina foi utilizado tanto para marcar uma continuidade com o modelo de civilização europeu no continente, como para reproduzir a exclusão de povos e culturas que, no período colonial, estavam localizados fora do modelo de humanidade desenhado pela colonialidade do poder.

Nesse momento, "América Latina" foi o nome eleito para denominar a restauração da "civilização" da Europa meridional, católica e latina na América do Sul e, ao mesmo tempo, reproduzir as ausências (dos índios e dos africanos) do primeiro período colonial, como afirma Mignolo (2007).

o fato de que fora a latinidade, e não a indianidade e a africanidade, a que se impôs como o nome do subcontinente tem simplesmente que ver com a circunstância que os que contaram a história eram descendentes de europeus e se identificaram com o sul de Europa e fundamentalmente com a França (Mignolo,2007:205). 
No processo de reorganização do sistema-mundo moderno-colonial e de realocação da América no contexto das disputas imperiais, a própria toponímia de muitos países latino-americanos que se formavam parece evidenciar a dimensão de colonialidade que atravessará o processo de constituição dos Estados-Nações no continente.

De maneira similar ao adjetivo "latina", os nomes de muitos países da região, ao mesmo tempo em que se referenciam em signos e símbolos do colonizador e do modelo de civilização europeu, excluem a possibilidade de participação de negros e índios no processo de formação dos Estados Nacionais. Em sua versão mais conhecida, por exemplo, a etimologia da palavra Venezuela significa pequena Veneza, fazendo alusão, portanto, à cidade italiana. E Colômbia, por sua vez, vem a significar terra de Cristovão Colombo (Otero, 2006).

Uma breve análise das toponímias dos países latino-americanos certamente poderia revelar a dimensão de colonialidade presente internamente em suas formações nacionais, caracterizando o que o sociólogo mexicano Pablo Gonzalez Casanova (2007) veio a denominar colonialismo interno. Para Mignolo (2003, 2005, 2007), o colonialismo interno se efetiva, justamente, com a reprodução da colonialidade do poder no âmbito dos Estados Nacionais em formação. Esse é um dos principais horizontes de expectativas que o conceito de América Latina ergue a partir de sua apropriação pela elite criolla de origem hispânica e portuguesa.

Neste cenário marcado por um entrecruzamento de interesses e influências dos desenhos imperiais franceses com as histórias locais das elites criollas, Mignolo (2007) destaca que o conceito de América Latina não se refere a uma realidade fixa e preexistente, onde os fatos e acontecimentos se dão. Para o autor, o surgimento do conceito de América Latina efetiva-se como um componente geopolítico de reorganização da colonialidade do poder no sistema mundo e da própria construção da idéia de modernidade. É no momento em que os processos de independência dos países sul-americanos começam a ocorrer e que a Península Ibérica encontra-se em decadência e fora da idéia de modernidade, que o conceito de América Latina é formulado e utilizado dentro da disputa de interesses geopolíticos mundiais, em articulação com interesses locais.

\section{Considerações finais}

Neste trabalho, buscamos oferecer algumas reflexões sobre o conceito de América Latina, evidenciando que este não pode ser compreendido como mera categoria de análise, destituída de atribuições 
valorativas que produzem consequências na forma como interpretamos e agimos na realidade.

Conscientes da dimensão de colonialidade, inerente ao conceito de América Latina, e as formas de desrespeito a ele vinculadas, bem como atentos ao fato de que as ideias e conceitos também constituem uma forma de ação no mundo e são engendradas por atores sociais específicos com interesses também específicos, talvez tenhamos a possibilidade de abrir espaço para conceituações que nos ofereçam horizontes de expectativas capazes de contemplar a diversidade de povos, histórias, lutas políticas e modos de vida que habitam nosso continente.

Nesse sentido, é imprescindível registrar que, atualmente, movimentos indígenas em todo continente, assim como populações de descendência africana e os próprios latinos residentes e nascidos nos Estados Unidos, têm deslocado o par conceitual América Latina/América Anglo-Saxônica. Esses grupos simplesmente não se posicionam em nome da América Latina ou de uma identidade fundada na latinidade porque também sofreram processos de exploração e expropriação pelos "latinoamericanos" - a elite criolla. Buscam, ao invés disso, estabelecer lutas em torno de outras identidades (Mignolo, 2007; Porto-Gonçalves, 2009).

Mobilizados diante dos inúmeros processos de expropriação que ainda hoje vêm sofrendo, os povos originários, por exemplo, têm questionado o caráter aparentemente a-histórico e apolítico com que o conceito de América Latina é empregado. Conscientes do conteúdo de dominação presente nesse nome, a expressão Abya-Yala ${ }^{2}$ vem sendo utilizada por este grupo como forma de autodesignar a região onde vivem (Mignolo, 2007; Porto-Gonçalves, 2009).

Ao reivindicarem uma nova forma de nomear e regionalizar o continente, confrontam o caráter eurocêntrico, racista e de classe do nome América Latina, bem como seu aspecto aparentemente neutro e destituído de valor e implicações políticas, abrindo, assim, um campo de disputa por uma regionalização que seja capaz de reconhecer suas histórias e territorialidades.

Neste período de celebração dos bicentenários de independência dos países latino-americanos, as fortes mobilizações dos povos indígenas de todo o continente na luta por otros bicentenários, têm explicitado este campo de conflitos e demonstrado que a "latinidade" não foi e não é capaz

\footnotetext{
${ }^{2}$ Abya-Yala na língua do povo Kuna significa "Terra madura", "Terra Viva" ou "Terra em florescimento.
} 
de representar a diversidade de povos que compõem o continente, mas, pelo contrário, reproduziu e reproduz a colonialidade do poder no âmbito interno dos países latino-americanos que se formaram a partir das independências do século XIX (Freitas, 2010).

\section{A LATINIDADE DO CONCEITO DE AMÉRICA LATINA}

Resumo: De uma maneira geral, assumimos de modo tão naturalizado as designações e os recortes geográficos das regiões que visualizamos em mapas ou que utilizamos como referência de pertencimento e localização, que dificilmente nos questionamos sobre os processos que instituíram esses nomes e desenhos cartográficos. $\mathrm{O}$ conceito de América Latina, habitualmente utilizado tanto na linguagem comum como em textos de jornais e trabalhos acadêmicos para denotar apenas uma localização geográfica guarda, no entanto, um forte sentido político. A partir da metodologia da História dos Conceitos e do diálogo com autores da perspectiva teórica do pensamiento decolonial, este trabalho busca recuperar e explicitar o conteúdo político e de ação no mundo presente sobre o conceito de América Latina.

Palavras-chave: América Latina; América; História dos Conceitos; Colonialidade do poder; Sistema Mundo Moderno-Colonial; Região.

\section{THE LATINITY OF THE CONCEPT OF LATIN AMERICA}

Abstract: In general, we assume in a naturalized way the designations and geographical delimitations of regions that we see on maps or that we use as reference of belonging and location, and barely question about the processes that have established these names and cartographic drawings. The concept of Latin America, usually used both in common language and in texts from newspapers and academic papers to denote only a geographic location holds, however, a strong political meaning. Based on the methodology of the History of Concepts and on the dialogue with the authors of the theoretical perspective of the pensamiento decolonial, this paper attempts to recover and clarify the political content and the content of the action in the world found in the concept of Latin America. 
Keywords: Latin America; history of concepts; coloniality of power; modern-colonial world system; region.

\section{BIBLIOGRAFIA}

CARDOSO, F. H. e FALLETO, E.. (1969). Dependencia y desarrollo en América Latina: Ensayo de Interpretación Sociológica. México: Siglo XXI.

CASTRO-GÓMEZ, S. e GROSFOGUEL, R. (2007). Prólogo. Giro decolonial, teoría crítica y pensamiento heterárquico. In: CASTROGÓMEZ, S. e GROSFOGUEL, R (eds.). El giro decolonial. Reflexiones para una diversidad epistémica más allá del capitalismo global. Bogotá: Iesco-Pensar-Siglo del Hombre Editores, p. 9-23.

DUSSEL, E. (2005). Europa, Modernidade e Eurocentrismo. In: LANDER, E. (ed.). A colonialidade do saber: eurocentrismo e ciências sociais. Buenos Aires: Clacso, p. 55-70.

ESCOBAR, A. (2003).Mundos y conocimientos de otro modo: el programa de investigación de modernidad/colonialidad Latinoamericano. Tabula Rasa, Bogotá, Universidad Colegio Mayor de Cundinamarca, $\mathrm{n}^{\circ}$, Janeiro/dezembro, p. 51-86.

FANON, F. (1965). Racismo y cultura. In: FANON, F. Por la revolución africana. México: Fondo de Cultura Económica, p.38-52.

FERES JÚNIOR, J. (2005). A história do conceito de Latin América nos Estados Unidos. Bauru, São Paulo: EDUSC.

FREITAS, G. (2010). Desafios para um continente de muitas faces. Entrevista Walter Mignolo. PROSA E VERSO. O Globo, 16 de Janeiro, p.3.

GONZÁLEZ CASANOVA, P. (2007). Colonialismo interno (uma redefinição). In: Boron, A. et al. (Org.).A teoria marxista hoje: Problemas $e$ perspectivas. Buenos Aires: ClacsoDisponível em: http://bibliotecavirtual.clacso.org.ar/ar/libros/campus/marxispt/cap. 19.doc Acesso: 10/09/2009.

JASMIM, M. G. (2005). História dos conceitos e teoria política e social: referências preliminares. Revista Brasileira de Ciências Sociais. São Paulo, vol.20, $\mathrm{n}^{\mathrm{o}}$ 57, p.27-38.Disponível

http://www.scielo.br/pdf/rbcsoc/v20n57/a02v2057.pdf

em: 16/10/2009. 
JASMIM, M. G. e FERES JÚNIOR, J. (2006) História dos Conceitos: dois momentos de um encontro intelectual. In: JASMIM, M. G. e FERES JÚNIOR, J. (Orgs.). História dos Conceitos: debates e perspectivas. Rio de Janeiro: Ed. PUC-Rio: Ed. Loyola: IUPERJ, p.9-38.

MALDONADO, N. (2007). Walter Mignolo: una vida dedicada al proyecto decolonial. Nómadas, Bogotá, Instituto de Estudios Sociales Contemporáneos (Iesco), nº 26, abril, p.187-194.

MASSEY, D. (2004). Filosofia e Política da Espacialidade: algumas considerações. Tradução: Rogério Haesbaert. GEOgraphia, Revista da Pós-Graduação em Geografia da UFF: Niterói, Vol.6, n 12, p.7-23.

MIGNOLO, W. D. (2003). Histórias Locais / Projetos Globais: Colonialidade, saberes subalternos e pensamento liminar. Belo Horizonte: UFMG.

. (2005) A colonialidade de cabo a rabo: O hemisfério Ocidental no horizonte conceitual da modernidade. In: LANDER, E. (ed.). $A$ colonialidade do saber: eurocentrismo e ciências sociais. Buenos Aires: Clacso, p.71-103.

. (2007) La idea de América Latina: La herida colonial y la opción decolonial. Barcelona: Gedisa.

MORAES, A. C. R. (2008). Território e História no Brasil. $3^{\text {a }}$ ed. São Paulo: Annablume.

OLIVEIRA, M. P. de. (1998). América Latina: legado socioespacial e globalização. In: HAESBAERT, R. (Org.). Globalização e fragmentação do mundo contemporâneo. Niterói: EdUFF, p.225-275.

OTERO, E. (2006) A Origem dos Nomes dos Países. São Paulo: Panda Books.

PORTO-GONÇALVES, C. W. (2002). Da geografia às geo-grafias: um mundo em busca de novas territorialidades. In: CECEÑA, A. E. e SADER, E. La Guerra Infinita: Hegemonía y terror mundial. Buenos Aires: Clacso, p.217-256.

. (2003). A Geograficidade do Social: uma contribuição para o debate metodológico sobre estudos de conflito e movimentos sociais na América Latina. In: SEONE, J. (Org.) Movimentos sociales y conflicto em América Latina. Buenos Aires: Clacso. Disponível em:

http://bibliotecavirtual.clacso.org.ar/ar/libros/osal/seoane/porto.rtf

Acesso em: 29/07/2009. 
. (2006). A Reinvenção dos Territórios: a experiência latinoamericana e caribenha. In: CECEÑA, A. E. (Org.). Los desafios de las emancipaciones en un contexto militarizado. Buenos Aires: Clacso, p.151197.

. (2009). Entre América e Abya-Yala - tensões de territorialidade. Desenvolvimento e Meio Ambiente, UFPR, n²0, jul./dez.,p.25-30.

QUIJANO, A. (2005). Colonialidade do poder, eurocentrismo e América Latina. In: LANDER, E.(ed.). A colonialidade do saber: eurocentrismo e ciências sociais. Buenos Aires: Clacso, p. 227-278.

. (2000) Colonialidad del poder y clasificación social. Journal of World-System Research. Volume XI, n ${ }^{\circ}$ 2, summer/fall, p. 342-386.

RESTREPO, E. e ROJAS, A. (2010). Inflexion decolonial: fuentes, conceptos y cuestionamientos. Popayán: Universidad del Cauca. Colección Políticas de la alteridad.

RICHTER, M. (2006). Avaliando um clássico contemporâneo: o Geschichtliche Grundbegriffe e a atividade acadêmica futura. In: JASMIM, M. G. e FERES JÚNIOR, J. (Orgs.). História dos Conceitos: debates e perspectivas. Rio de Janeiro: Ed. PUC-Rio: Ed. Loyola: IUPERJ, p.39-53. ROUQUIÉ, A. (1992). O extremo-ocidente: introdução à America Latina. São Paulo: Edusp.

Data de submissão: 19/09/2011

Data de aprovação: 20/05/2012 